\title{
Pengujian Kandungan Boraks dan Formalin Pada Makanan Dengan Menggunakan Simple Methods Di Kelompok PKK Km. 13 Pondok Meja
}

\author{
Heriyanti, Restina Bemis, Rahmat Basuki \\ Program Studi DIII Kimia Industri \\ Email: heriyanti@unja.ac.id; bemisrestina@gmail.com; rahmaduki@gmail.com
}

\begin{abstract}
Abstrak: Dewasa ini boraks dan formalin banyak sekali digunakan dalam industri makanan, seperti: dalam pembuatan mie basah, tahu putih, tahu kuning, bakso, sosis, dan ikan asin. Padahal zat kimia ini merupakan bahan beracun dan bahan berbahaya bagi manusia sehingga sangat dilarang digunakan sebagai bahan baku makanan. Kebanyakan masyarakat mengira bahwa pengujian boraks dan formalin dalam makanan yang dapat dibuktikan kebenarannya, harus dilakukan di laboratorium sehingga memerlukan biaya mahal, padahal ada beberapa cara sederhana yang dapat dilakukan tanpa harus melakukannya di laboratorium. Sehingga perlu adanya alternatif cara identifikasi kandungan boraks maupun formalin pada makanan dengan cara yang sederhana (simple method) dan bisa dilakukan di rumah menggunakan bahan-bahan yang ada di sekitar kita tanpa harus dilakukan di laboratorium dengan menggunakan bahan-bahan kimia. Dalam kegiatan ini, alternatif yang bisa dilakukan yaitu menggunakan kunyit untuk identifikasi boraks dan getah pepaya muda untuk identifikasi formalin. Target kegitan pengabdian kepada masyarakat yang ingin dicapai adalah : (1) memberikan pengetahuan tentang bahaya boraks dan formalin bagi kesehatan; (2) memberikan informasi melalui penyuluhan tentang ciri-ciri makanan yang mengandung boraks dan formalin; (3) pelatihan tentang pengujian bahan makanan yang mengandung boraks dan formalin menggunakan simple method; (4) mitra mempu menerapkan cara pengujian boraks dan formalin di kehidupan sehari-hari sehingga kesehatan keluarga lebih terjamin.
\end{abstract}

Kata kunci: Boraks, Formalin, Pengawet

\section{PENDAHULUAN}

Akibat kemajuan ilmu teknologi pangan di dunia dewasa ini, maka semakin banyak jenis bahan makanan yang diproduksi, dijual, dan dikonsumsi dalam bentuk yang lebih awet dan lebih praktis dibandingkan dengan bentuk segarnya. Berkembangnya produk pangan awet tersebut hanya mungkin terjadi karena semakin tingginya kebutuhan masyarakat perkotaan terhadap berbagai jenis makanan yang praktis dan awet.

Kebanyakan makanan yang dikemas mengandung bahan tambahan, yaitu suatu bahan yang dapat mengawetkan makanan atau merubahnya dengan berbagai teknik dan cara. Bahan tambahan makanan didefinisikan sebagai bahan yang tidak lazim dikonsumsi sebagai makanan dan biasanya bukan merupakan komposisi khas makanan, dapat bernilai gizi atau tidak bernilai gizi, ditambahkan ke dalam makanan dengan sengaja untuk membantu teknik pengolahan makanan.

Dewasa ini boraks dan formalin banyak sekali digunakan dalam industri makanan, seperti: dalam pembuatan mie basah, tahu putih, tahu kuning, bakso, sosis, dan ikan asin. Padahal zat kimia ini merupakan bahan beracun dan bahan berbahaya bagi manusia sehingga sangat dilarang digunakan sebagai bahan baku makanan. Boraks dan formalin adalah bahan kimia baik dalam bentuk tunggal maupun campuran yang dapat membahayakan kesehatan dan lingkungan hidup secara langsung atau tidak langsung yang mempunyai sifat racun, karsinogenik, teratogenik, mutagenik, korosif dan iritasi (Peraturan Menteri Kesehatan Nomor: 472/ Menkes/Per/V/ 1996 tentang Pengamanan Bahan Berbahaya Bagi Kesehatan).

Kebanyakan masyarakat mengira bahwa pengujian boraks dan formalin dalam makanan yang dapat dibuktikan kebenarannya, harus dilakukan di laboratorium sehingga 
memerlukan biaya mahal, padahal ada beberapa cara sederhana yang dapat dilakukan tanpa harus melakukannya di laboratorium.

Sehingga perlu adanya alternatif cara identifikasi kandungan boraks maupun formalin pada makanan dengan cara yang sederhana (simple method) dan bisa dilakukan di rumah menggunakan bahan-bahan yang ada di sekitar kita tanpa harus dilakukan di laboratorium dengan menggunakan bahan-bahan kimia. Dalam kegiatan ini, alternatif yang bisa dilakukan yaitu menggunakan kunyit untuk identifikasi boraks dan getah pepaya muda untuk identifikasi formalin.

Informasi mengenai mengenai cara pengujian boraks dan formalin ini penting bagi ibu-ibu rumah tangga sehingga bisa memberikan makanan yang aman dikonsumsi untuk keluarga. KM. 13 Desa Pondok Meja merupakan desa yang berbatasan langsung dengan Kota Jambi. Sebagian besar penduduk Desa Pondok Meja bermata pencaharian sebagai petani karet dan juga sebagai buruh tani, sebagian lainya sebagai buruh bangunan, berdagang, dan sebagian kecil sebagai pegawai negeri dan pegawai swasta. Sementara aktivitas ibu-ibu sebagian besar berprofesi sebagai ibu rumah tangga.

\section{METODE PELAKSANAAN}

\subsection{Alat dan Bahan}

Alat-alat yang digunakan adalah gelas, sendok, mangkuk, pisau, ember, tusuk gigi, alas potong.

Bahan yang digunakan dalam kegiatan ini berupa bahan makanan yang akan diuji dan bahan yang digunakan untuk menguji boraks dan formalin. Bahan makanan yang diuji berupa mie basah, tahu putih, tahu kuning, bakso, sosis, dan ikan asin. Bahan yang digunakan untuk menguji boraks dan formalin kunyit, air, tisu, papaya,

\subsection{Pengujian Boraks}

Langkah-langkah dalam uji bahan makanan yang mengandung boraks dengan kunyit yaitu dengan menghaluskan lima ruas kunyit dengan parut di dalam baskom kecil. Beri air secukupnya pada kunyit yang telah diparut. Letakkan kertas tisu pada nampan kemudian masukkan ekstrak hingga menyerap ekstrak secara keseluruhan dan letakkan di nampan yang bersih. Kemudian jemur kertas tisu di bawah terik matahari.

Bakso yang sudah disiapkan ditumbuk hingga menjadi ekstrak dengan diberi sedikit air. Air ekstrak tersebut kemudian diteteskan pada kertas whatman tadi. Jika kertas whatman berubah menjadi warna coklat maka bakso tersebut mengandung boraks.

Pengujian boraks juga bisa dilakukan dengan menggunakan tusuk gigi dengan cara menusukkan tusuk gigi pada kunyit terlebih dahulu. Kemudian tusukkan pada bakso yang akan diuji. Setelah sekitar 5 detik, maka akan terlihat apakah bakso tersebut mengandung boraks atau tidak. Tandanya, jika bakso tersebut mengandung boraks, maka tusuk gigi akan berwarna orange kemerah-merahan. Hal ini disebabkan karena kunyit akan bereaksi terhadap bahan kimia, termasuk boraks. Perlakuan yang sama juga dilakukan untuk mie basah, tahu putih, dan tahu kuning. 


\subsection{Pengujian Formalin}

Pengujian formalin dilakukan dengan menggunakan getah papaya. Caranya dengan mencari buah pepaya muda, lalu diiris bagian buahnya hingga menghasilkan getah (cairan getah). Selanjutnya sampel uji (mie basah, tahu putih, tahu kuning, dan ikan asin) ditetesi getah papaya. Jika getah papaya mengalami perubahan dari cair ke menggumpal bearti sampel terbukti positif formalin.

Pengujian boraks dan formalin juga dilakukan secara visual dengan memperhatikan ciri fisik dari bahan uji seperti :

Mie Basah yang mengandung boraks :

- Teksturnya sangat kenyal

- Biasanya lebih mengkilat, tidak lengket dan tidak cepat putus.

Bakso mengandung boraks:

- Teksturnya sangat kenyal

- Warnanya tidak kecokelatan seperti penggunaan daging namun lebih cenderung keputihan

\section{HASIL YANG DICAPAI}

\subsection{Pertemuan Tim Pelaksana PPM dengan Mitra}

Kegiatan ini diawali dengan melakukan koordinasi dengan pihak desa dilakukan dengan Ibu Kepala Desa Pondok Meja tetang kegiatan PPM dengan judul "Pengujian Kandungan Boraks Dan Formalin Pada Makanan Dengan Menggunakan Simple Methods Di Kelompok PKK Km. 13 Pondok Meja". Pertemuan ini dilakukan guna membahas rencana kegiatan pengabdian yang akan dilakukan seperti penyuluhan tentang bahaya penggunaan boraks dan formalin pada makanan, ciri-ciri makanan yang mengandung boraks dan formalin, dan melakukan pengujian terhadap beberapa bahan makanan yang mengandung boraks dan formalin menggunakan metoda yang sederhana. Hasil koordinasi denga Ibu Kepala Desa Pondok Meja adalah mereka menyambut baik dan bersedia menjadi mitra dalam pelaksanaan kegiatan PPM ini.

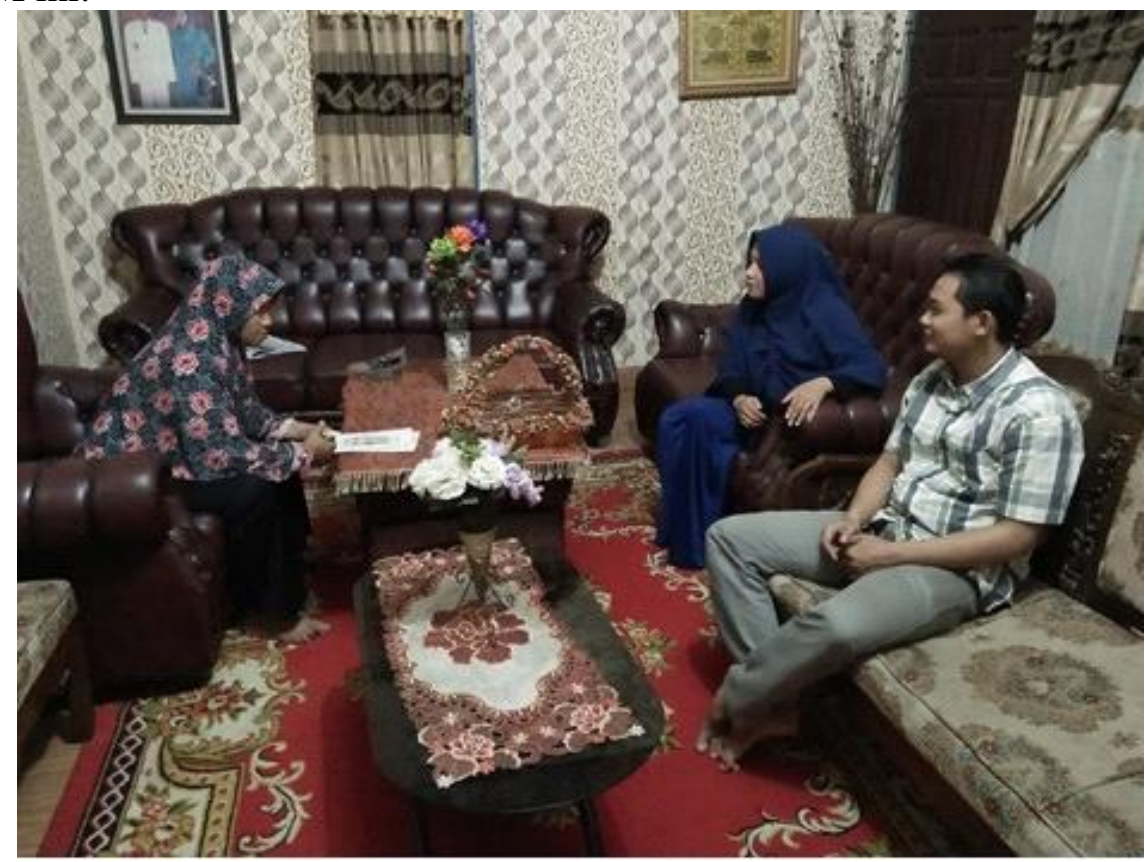

Gambar 1. Pertemuan TIM pengabdian dengan Mitra 
Sasaran dari kegiatan PPM ini adalah ibu-ibu PKK Desa Pondok Meja dengan tujuan agar mereka ikut berpartisipasi dalam kegiatan PPM dan memiliki pengetahuan dan pemahaman tentang bahaya boraks dan formalin pada makanan, mengetahui ciri-ciri makanan yang mengandung boraks dan formalin, mampu melakukan uji boraks dan formalin pada makanan dengan menggunakan simple methods.

\subsection{Kegiatan Penyuluhan dan Pengujian Boraks dan Formalin pada Makanan}

Kegiatan penyuluhan dan pengujian boraks dan formalin pada makanan dilakukan di Gedung Pertemuan Pemerintah Desa Pondok Meja, Kecamatan Mestong, Kabupaten Dusun Purwodadi Muaro Jambi dan Desa Pondok Meja. Kegiatan diawali dengan penyuluhan tentang bahaya penggunaan boraks dan formalin pada makanan, ciri-ciri makanan yang mengandung boraks dan formalin, dan cara pengujian terhadap beberapa bahan makanan yang mengandung boraks dan formalin menggunakan simple method. Ibu-ibu PKK sangat antusias dan aktif dalam mengikuti kegiatan ini. Hal ini terlihat dari banyaknya pertanyaan yang disampaikan pada tim pelaksana.



Gambar 2. Sosialisasi ke Ibu-Ibu PKK Desa Pondok Meja

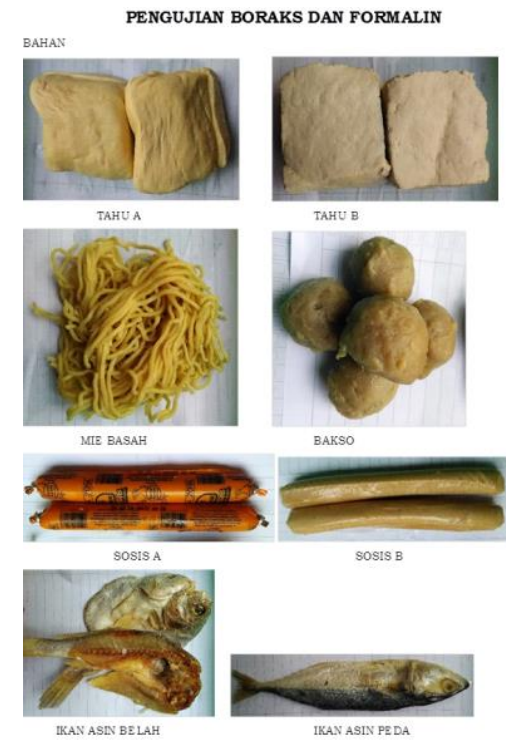

Gambar 3. Bahan-bahan Uji 
Setelah penyampaian materi, kegiatan dilanjutkan dengan pengujian langsung makanan yang tidak mengandung boraks dan formalin dan makanan yang sudah diberikan boraks dan formalin. Bahan makanan yang diuji berupa mie basah, tahu putih, tahu kuning, bakso, sosis, dan ikan asin. Kegiatan ini dilakukan agar Ibu-ibu PKK dapat melakukan langsung cara pengujian,dan mengetahui perbedaan makanan yang tidak atau mengandung boraks dan formalin.

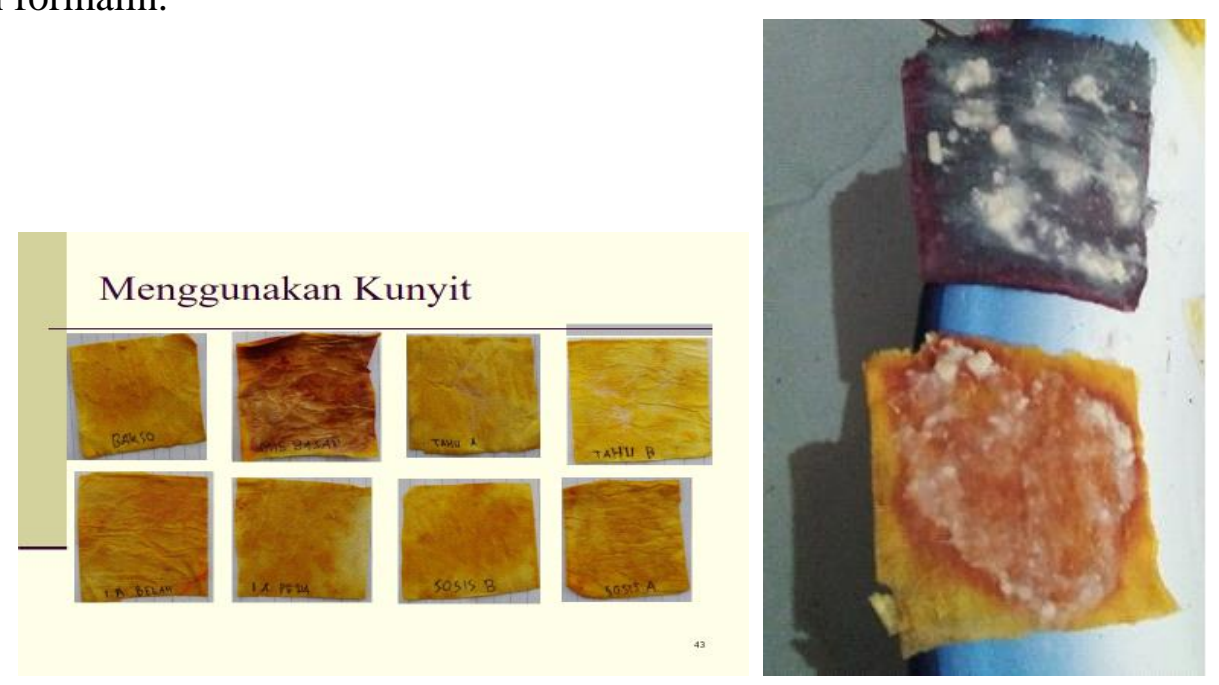

Gambar 4. Hasil Pengujian terhadapan beberapa sampel dengan menggunakan kunyit

\section{KESIMPULAN}

Metode pengujian kandungan boraks dan formalin pada makanan dengan menggunakan simple methods yang diperkenalkan menjadi pengetahuan untuk masyarakat untuk menguji makanan yang akan dikonsumsi. Metode ini juga memberikan pengetahuan cara membedakan makanan yang mengandung boraks dan formalin. Kegiatan PPM ini mendapat respon positif dari mitra yaitu warga, khususnya oleh Ibu-Ibu PKK Desa Pondok Meja

\section{UCAPAN TERIMA KASIH}

Ucapan terima kasih penulis sampaikan kepada Universitas Jambi yang telah mendanai program pengabdian ini dari dana DIPA UNJA Tahun 2018. Ucapan terima kasih juga disampaikan pada pihak mitra yaitu Pejabat Desa dan PKK Desa Pondok Meja, Kecamatan Mestong, Kabupaten Dusun Purwodadi Muaro Jambi, Provinsi Jambi.

\section{DAFTAR PUSTAKA}

Menkes RI. 1976. Peraturan Menteri Kesehatan RI No 329/Menkes/PER/XII/76 tentang Produksi dan Peredaran Makanan, Jakarta: Depkes

Menkes RI. 1988. Peraturan Menteri Kesehatan RI No 722/Menkes/PER/XII/88 tentang Bahan Tambahan Makanan, Jakarta: Depkes

Menkes RI. 1996. Peraturan Menteri Kesehatan Nomor : 472/ Menkes/ Per/ V/ 1996 tentang Pengamanan Bahan Berbahaya Bagi Kesehatan, Jakarta: Depkes 
Winarno, F. G., Rahayu, T.S., 1994. Bahan Tambahan untuk Makanan dan Kontaminan. Jakarta: Pustaka Sinar Harapan

Winarno, F. G., 1991. Kimia Pangan dan Gizi. Jakarta: PT. Gramedia Pustaka Utama 